\title{
A controlled clinical trial of alpha methyl dopa in Parkinsonian tremor
}

\author{
D. O. MARSH, H. SCHNIEDEN, AND JOHN MARSHALL \\ From the Institute of Neurology and National Hospital for Nervous Diseases, \\ Queen Square, London
}

The large number of drugs used in the treatment of Parkinsonism is an eloquent testimonial to the fact that the therapy of this condition leaves much to be desired.

Clinical experience indicates that although anticholinergic compounds, to which class most drugs used in Parkinsonism belong, have a beneficial effect on the rigidity of Parkinsonism, their effect on tremor is not so pronounced (Doshay, 1961; Barbeau, 1962). It is therefore desirable that drugs other than the anticholinergic group, which offer some prospect of being effective against tremor, should be tried.

The present report is concerned with the clinical trial of one such drug, $\alpha$ methyl dopa, which is being extensively used in the management of hypertension. $\alpha$ Methyl dopa inhibits the formation of dopamine and 5-hydroxytryptamine. The latter produces tremor when administered intraventricularly to cats (Domer and Feldberg, 1960) and in mice this tremor can be inhibited by pre-treatment with $\alpha$ methyl dopa (Schnieden, 1963). These facts made it not unreasonable to study the effect of $\alpha$ methyl dopa in Parkinsonism.

\section{METHODS}

The effects of the drug were studied by giving an acute dose while observing the patients clinically and recording the tremor graphically, and by means of a double-blind trial.

Tremor was measured by means of a valve sensitive to acceleration which the patient held in his hand. Movement of the valve upset the balance of a bridge circuit and the electrical output after amplification was recorded by a pen writer on moving paper. From the tracings obtained a number of random samples (at least six), each of 5 seconds' duration, was obtained using random number tables. The maximum amplitude of the tremor record in each sample was noted and the mean maximum amplitude was calculated for periods before and after administration of the drug. The percentage increase or decrease in the mean maximum amplitude following administration of the drug was then calculated. Since by Newton's law of motion force is equal to mass times acceleration, and since over the period of recording the mass of the arm plus the valve remains constant, acceleration, as measured by the amplitude of the tracing, is proportional to the force producing the tremor. The change in amplitude of the tracing after administration of the drug is, therefore, a measure of the change in the force producing the tremor. Full details of the apparatus used are given by Marshall and Walsh (1956).

A number of other tests were also used. The patient was required to pick up five numbered marbles placed in a row in front of five numbered holes and to drop them as quickly as possible through their respective holes, the time taken to perform this task being recorded. This will be referred to as the 'marble test'. The test was repeated three times and the mean value taken.

The patient was asked to walk a distance of 10 feet and also to turn completely around, as quickly as possible, the time taken being noted. These tests were also repeated three times and the mean values obtained.

The trial was conducted over four periods each of one week. During each period the patient was given 1.0 or $1.5 \mathrm{~g}$. of either $\alpha$ methyl dopa or a placebo of identical appearance, the order of administration being decided by random tables. Neither the patient nor the investigators knew which substance was being given. Each patient continued to take his previous medication which included benzhexol (Artane), orphenadrine (Disipal), benztropine (Cogentin), and ethopropazine (Lysivane).

Three methods of assessing the results were employed, the subjective impression of the patient himself, a clinical assessment by one observer, and recordings of the tremor made by a second observer. These assessments were made at weekly intervals.

The subjective impressions of the patients about the degree of tremor and any side-effects were carefully noted. Blood pressure and weight were recorded and the degree of tremor in each limb was assessed clinically according to the scale: grade 0 , no tremor; grade 1, occasional and mild tremor; grade 2 , moderate tremor; grade 3 , severe tremor. The degree of rigidity in the limbs was assessed by passive movements and any change in mood was noted. Tremor recordings were made at the end of each visit. These were not discussed until the end of the trial when the patient's own assessments, the clinical assessments, and the tremor recordings were compared and correlated.

As anxiety and cold may affect performance in Parkinsonism, patients were enabled to become familiar 
I. CONTROL
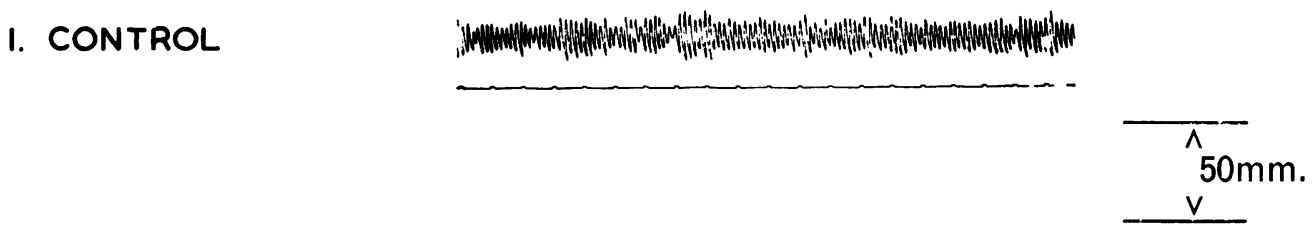

2. 6HR. AFTER DRUG

FIG. 1. Course of tremor following $2 \mathrm{~g}$. $\alpha$ methyl dopa given orally to a Parkinsonian patient (male aged 56). Note marked diminution of tremor at six and eight hours after administration of the drug.

\section{8HR. AFTER DRUG}

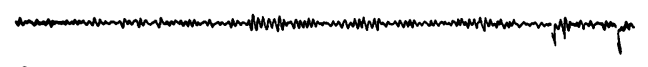

Patient taken off anti-Parkinsonian drugs.

\section{26 HR. AFTER DRUG}

with the tests before measurements were made and all were carried out in a room at a temperature of approximately $22^{\circ} \mathrm{C}$.

For the acute study patients were given on separate days a dose of $\alpha$ methyl dopa, $2 \mathrm{~g}$. orally, or a placebo. The tremor was recorded before and from two hours to 10 hours after administration of the drug.

In the double-blind trial five men and six women with ages ranging from 44 to 70 years were invited to participate; all accepted, but one withdrew before completing the trial. Five were severely affected by the disease and had such a degree of tremor, rigidity, and difficulty in walking that they were unable to work and spent most of their time sitting in chairs. Three patients who had only suffered from the condition for three or four years had only mild tremor and were able to work full time. The remaining three patients had an intermediate degree of disablement.

\section{RESULTS}

EFFECT OF 2 G. $\alpha$ METHYL DOPA ORALLY Following an acute oral dose of $2 \mathrm{~g}$. of $\alpha$ methyl dopa a marked diminution in the amplitude of tremor was observed (Fig. 1). This began about four hours after administration of the drug and persisted for periods of at least six hours (Fig. 2). Ten patients were studied in all, cases 1 to 7 being maintained on their usual anti-Parkinsonism drugs, whereas cases a to c had their usual therapy withdrawn. Several patients showed some response to the placebo (Fig. 3) but in all except case 5 this was slight as compared with the response to the drug. Case 5 volunteered the following history. She stated that about 14 hours after the test finished, that was about 20 hours after the dose had been given, she felt slightly drowsy and her tremor diminished quite dramatically, so much so, to quote her own words, 'for the first time in years I was able to lift the telephone without my hand trembling'. It is of interest that this patient had a history of gastro-intestinal disease (duodenal

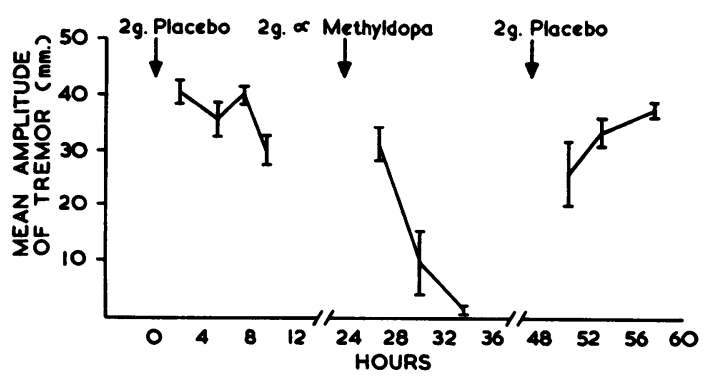

FIG. 2. Effect of placebo (2 g.) or a methyl dopa (2 g.) given orally on mean amplitude of tremor (mean $\pm S . E$.) in a Parkinsonian patient. Tremor amplitude at five and 10 hours after administration of a methyl dopa is significantly less than that recorded during first placebo day. Effect appears to continue for over 24 hours. Patient was taken off anti-Parkinsonian drugs before treatment began. 

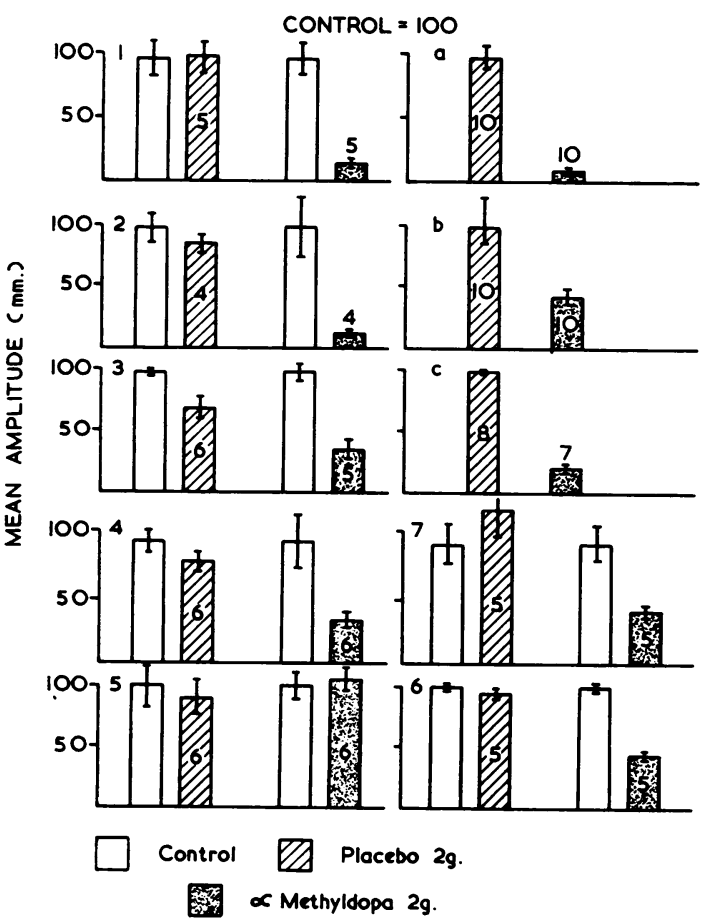

FIG. 3. Effect of a single dose of $2 \mathrm{~g}$. a methyl dopa or placebo on Parkinsonian tremor in seven patients ( 1 to 7$)$ on anti-Parkinsonian drugs and three patients (a to c) off drugs. Placebo and $\alpha$ methyl dopa responses are expressed as a percentage of control amplitude (mean \pm S.E.). Figures in or above histograms refer to time of recording (hours after administration of drugs). ulcer) and it is possible that for some reason absorption was delayed. A similar history was not given following administration of the placebo.

The maximum fall of systolic blood pressure recorded following the $2 \mathrm{~g} . \alpha$ methyl dopa was $20 \mathrm{~mm}$. $\mathrm{Hg}$. One patient did complain of weakness and slight giddiness on standing.

Two patients were so impressed by the results of the acute test that they volunteered to continue to take 2 g. daily. After a few days on this dosage, however, they became drowsy, and one became depressed and developed symptoms of postural hypotension. The drug was therefore stopped after 14 days, although at the time of stopping the beneficial effects on the tremor were still present. Following this a double-blind trial using a smaller dose of the drug ( $1 \mathrm{~g}$. daily) was organized.

DOUBLE-BLIND TRIAL OF $\alpha$ METHYL DOPA The $\alpha$ methyl dopa and the placebo were labelled $A$ and $B$, the identity of each being unknown to patients and observer. Each patient was given $1 \mathrm{~g}$. of A or B in their first week on each, the dose being increased to $1.5 \mathrm{~g}$. in the second period on each if no untoward symptoms occurred. The results are shown in Table I and Figure 4. This shows that in five of the 10 patients who completed the trial the patient's assessment, the clinical assessment, and the tremor recording are in agreement in preferring $\mathbf{B}$ to $A$.

In four patients $B$ was preferred by one or two of the assessments: the remainder shows no difference between $A$ and $B$. In only one patient (case 10) was A found better than B by the patient's own

TABLE I

DATA ON PARKINSONIAN PATIENTS PARTICIPATING IN DOUBLE-BLIND TRIAL

\begin{tabular}{|c|c|c|c|c|c|c|c|c|c|c|}
\hline \multirow{2}{*}{$\begin{array}{l}\text { Case } \\
\text { No. }\end{array}$} & \multirow[t]{2}{*}{$A g e^{\prime}$} & \multirow[t]{2}{*}{ Sex } & \multirow{2}{*}{$\begin{array}{l}\text { Duration } \\
\text { of Disease } \\
(y r .)\end{array}$} & \multirow[t]{2}{*}{ Severity } & \multirow{2}{*}{$\begin{array}{l}\text { Baseline Medication } \\
\text { (daily dose in mg.) }\end{array}$} & \multicolumn{2}{|c|}{ Blood Pressure (mm. $\mathrm{Hg})$} & \multicolumn{3}{|c|}{ Effect of Methyl Dopa Judged by } \\
\hline & & & & & & Highest & Lowest & $\begin{array}{l}\text { Patients } \\
\text { Assessment }\end{array}$ & $\begin{array}{l}\text { Clinical } \\
\text { Assessment }\end{array}$ & $\begin{array}{l}\text { Tremor } \\
\text { Recording }\end{array}$ \\
\hline 1 & 52 & $\mathbf{M}$ & 16 & Severe & $\begin{array}{l}\text { Artane, } 6 \\
\text { Cogentin, } 2\end{array}$ & $160 / 100$ & $150 / 90$ & B & Same & $\mathbf{B}^{2}$ \\
\hline 2 & 44 & $\mathbf{M}$ & 4 & Severe & Artane, 12 & $145 / 75$ & $150 / 90$ & Same & Same & $\mathbf{B}^{1}$ \\
\hline 3 & 68 & $\mathbf{F}$ & 7 & Severe & Artane, 12 & $140 / 75$ & $130 / 70$ & B & B & $\mathbf{B}^{2}$ \\
\hline 4 & 70 & $\mathbf{F}$ & 10 & Moderate & $\begin{array}{l}\text { Artane, } 6 \\
\text { Cogentin, } 2 \\
\text { Lysivane, } 150\end{array}$ & $170 / 90$ & $160 / 90$ & B & $\mathbf{B}$ & $\mathbf{B}^{2}$ \\
\hline 5 & 51 & $\mathbf{F}$ & 3 & Mild & $\begin{array}{l}\text { Disipal, } 200 \\
\text { Chloropropamide, } 200\end{array}$ & $150 / 85$ & $125 / 75$ & $\mathbf{B}$ & B & $\mathbf{B}^{2}$ \\
\hline 6 & 59 & $\mathbf{M}$ & 6 & Moderate & Cogentin, 6 & $150 / 90$ & $145 / 85$ & B & $\mathbf{B}$ & $\mathbf{B}^{1}$ \\
\hline 7 & 54 & $\mathbf{M}$ & 4 & Mild & Artane, 4 & $165 / 105$ & $155 / 100$ & B & B & Same \\
\hline 8 & 45 & $\mathbf{F}$ & 17 & Severe & Artane, 10 & $120 / 65$ & $115 / 80$ & $\mathbf{B}$ & $\mathbf{B}$ & Same \\
\hline 9 & 62 & $\mathbf{F}$ & 3 & Moderate & Artane, 6 & $180 / 100$ & $175 / 100$ & \multicolumn{3}{|c|}{ Withdrew from trial } \\
\hline 10 & 62 & $\mathbf{F}$ & 5 & Severe & $\begin{array}{l}\text { Artane, } 8 \\
\text { Disipal, } 100\end{array}$ & $150 / 90$ & $140 / 85$ & $\mathbf{A}$ & Same & $\mathbf{A}^{1}$ \\
\hline 11 & 52 & $\mathbf{M}$ & 4 & Mild & $\begin{array}{l}\text { Lysivane, } 300 \\
\text { Cogentin, } 4\end{array}$ & $120 / 75$ & $120 / 75$ & $\mathbf{B}$ & $\mathbf{B}$ & $\mathbf{B}^{2}$ \\
\hline
\end{tabular}

${ }^{1} B$ significantly different from $A$ at high dose only $(P<0.05)$.

${ }^{2} B$ significantly different from $A$ at both dose levels used $(P<0.05)$. 

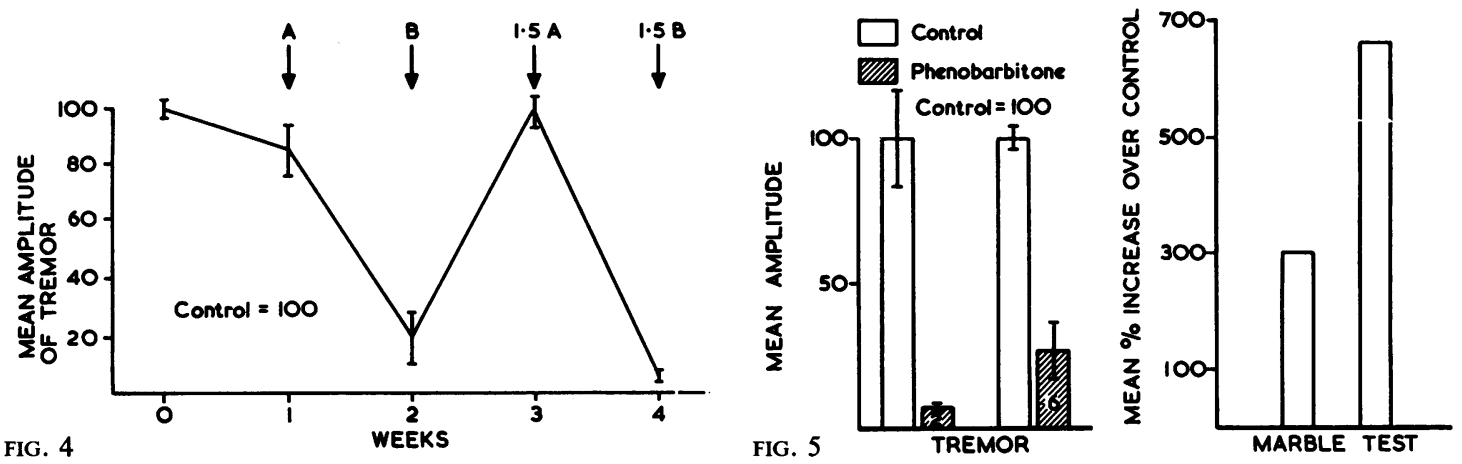

FIG. 4. Effect of $1 \mathrm{~g}$. of $A$ or $B$ or $1.5 \mathrm{~g}$. A or B on Parkinsonian tremor (double-blind trial). B was in fact $\alpha$ methyl dopa. Results expressed as percentage of control amplitude (mean $\pm S . E$.).

FIG. 5. Effect of phenobarbitone (180 mg.) on Parkinsonian tremor and on the 'marble' test in two patients with Parkinsonism. Results expressed as percentage of control. Figures in histograms refer to time of recording (hours after administration of drug).

assessment and by the measurement of the amplitude of tremor. In fact B was $\alpha$ methyl dopa and A the placebo. Slight improvement was reported by some patients after taking $A$ but eight of the 10 patients were in no doubt that B was markedly better than $A$.

Clinical assessment correlated well with the patients' subjective assessment in that when they reported a subjective improvement in most cases supporting clinical and objective evidence was present, but in some cases when a subjective improvement was reported no clinical or objective improvement was noted. It must be pointed out, however, that clinical and objective assessment was based on an examination or recording once weekly whereas the patient's subjective assessment was based on the whole week.

SIDE-EFFECTS NOTED DURING THE TRIAL No sideeffects of any type were experienced while $A$ was being taken but with $\mathrm{B}$ significant complaints were encountered (Table II).

\section{TABLE II}

SIDE-EFFECTS IN 11 PATIENTS ON B ( $\alpha$ METHYL DOPA) DURING DOUBLE-BLIND TRIAL

Side-effects Noted

No. of Cases

$\begin{array}{ll}\text { Sedation present } & 5 \\ \text { Change of mood (depression) } & 3 \\ \text { Faintness } & 2 \\ \text { Dry mouth } & 2 \\ \text { Diminution in bowel frequency } & 1\end{array}$

One patient (case 9) became extremely drowsy after $0.75 \mathrm{~g}$. of $\mathrm{B}$ and asked to withdraw from the trial. Two patients were mildly drowsy on $1 \mathrm{~g}$. of $\mathbf{B}$. Three patients who had previously been subject to mild attacks of depression became profoundly depressed, with loss of appetite, tearfulness, and insomnia after the dose of $1.5 \mathrm{~g}$. The fall in blood pressure on the dosage of up to $1.5 \mathrm{~g}$. daily was minimal (see Table I). There were no complaints of indigestion, diarrhoea, nasal stuffiness, or nightmares, and no significant changes in weight or in the white cell count.

In order to assess the contribution the sedative action of the drug was making to the results, the effect of $180 \mathrm{mg}$. phenobarbitone given orally was compared with 2 g. $\alpha$ methyl dopa in five patients. The phenobarbitone produced as much if not more drowsiness than did the $\alpha$ methyl dopa, and also reduced tremor to as little as $10 \%$ of the normal level. One difference emerged in some of the patients which appears of interest. $\alpha$ Methyl dopa had no appreciable effect on the ability of patients to do the "marble test', walk a set distance, or turn. However, as can be seen from Fig. 5, phenobarbitone certainly increased the time to complete the 'marble test' in two patients.

\section{DISCUSSION}

There are many possible explanations as to why $\alpha$ methyl dopa reduced Parkinsonian tremor and further study is necessary before many of these suggestions can be eliminated. Dryness of the mouth occurs in hypertensive patients treated with $\alpha$ methyl dopa, which suggests that this compound may have some anticholinergic action. If so, this action is extremely small since the compound in doses of $200 \mathrm{mg}$. $/ \mathrm{kg}$. (doses used in man were about 20 to $30 \mathrm{mg} . / \mathrm{kg}$.) has no effect on tremorine-induced 
tremor in mice, tremorine having a marked cholinergic action (Everett, 1961; Schnieden, 1963).

Another possibility is that the effect may be mediated by changes in the catecholamine content of the brain produced by the drug. In experimental animals Carmichael, Feldberg, and Fleischhauer (1962) found that dopamine inhibited tremor; it might therefore be expected that $\alpha$ methyl dopa would increase tremor. However, these authors point out that their experimental model may not be a good model for the assay of drugs for Parkinsonism.

McGeer, Boulding, Gibson, and Foulkes (1961) concluded that dopa had nothing to offer in the treatment of drug induced Parkinsonism. On the other hand, Birkmayer and Hornykiewicz (1961) and Barbeau (1962) have reported that dopa does improve Parkinsonian akinesia and rigidity, although Barbeau (1962) also states that $\alpha$ methyl dopa increases Parkinsonian tremor, a finding which differs from that noted in the present study.

At first sight it might seem incompatible that both $\alpha$ methyl dopa and dopa could improve the symptoms encountered in Parkinsonism. But this difficulty only applies if the catecholamine pathway is considered. If, for instance, the mechanism of action was on the formation of 5-hydroxytryptamine both $\alpha$ methyl dopa and dopa would inhibit 5-hydroxytryptamine formation by acting as alternative substitutes or inhibitors for the decarboxylase involved. It is of interest that both $\alpha$ methyl dopa and dopa will experimentally inhibit the head twitch response to 5-hydroxytryptamine in mice (Corne, Pickering, and Warner, 1963).

Low urinary dopamine concentrations have recently been found to occur in Parkinsonism (Barbeau, 1962) but the significance of this in relation to the present study is difficult to interpret, as urinary dopamine may not be an index of the dopamine content of the brain, although low dopamine and low 5-hydroxytryptamine concentrations are known to occur in the basal ganglia of Parkinsonian patients.

Other possible explanations for the action of $\alpha$ methyl dopa are that changes in blood pressure or cardiac output may have produced the modified tremor response observed. A fall in blood pressure does not necessarily reduce tremor (Barcroft, Peterson, and Schwab, 1952; Constas, 1962). Moreover in our series tremor depression was observed in patients in whom negligible changes in blood pressure occurred.

Whilst changes in cardiac output are known to influence physiological tremor (Brumlik, 1962) the importance of this factor in Parkinsonian tremor is not yet clear. Sannerstedt, Varnauskas, and Werkö (1962) and Dollery, Harrington, Hodge, and
McMichael (1963) have found no significant effect of $\alpha$ methyl dopa on the cardiac output of hypertensive patients. However, Onesti, Brest, Novack, and Moyer (1962) did report that the cardiac output was reduced by $\alpha$ methyl dopa. In physiological tremor the rise in cardiac output has been shown to increase tremor, and therefore in view of the findings of Onesti et al. (1962) it is possible that a diminution in cardiac output caused by $\alpha$ methyl dopa may play a part in diminishing the tremor of Parkinsonian patients.

How far drowsiness is linked with the antitremor action of $\alpha$ methyl dopa may become clear in a long-term trial of the compound. In hypertensive patients tested with the drug drowsiness is common in the first weeks, but then disappears. It is our impression that a similar development may occur in Parkinsonism.

The role of the drug in the treatment of Parkinsonism is difficult to assess as yet. The lack of a drug which is clearly effective in controlling tremor makes it important to explore any avenue that offers a possibility of therapeutic benefit. The initial observations with $\alpha$ methyl dopa certainly justify further study of its place in the treatment of Parkinsonism. Although we did not carry out any specific tests on the effect of the drug on rigidity, our impression was that it was without influence. The drug should therefore be prescribed in any therapeutic trial together with drugs known to affect rigidity.

\section{SUMMARY}

$\alpha$ Methyl dopa given orally in a dose of $2 \mathrm{~g}$. depresses Parkinsonian tremor, the effect being greater than that obtained with a placebo. With this dose mild orthostatic symptoms and drowsiness occurred in some patients. In a double-blind trial, smaller doses of 1 to $1.5 \mathrm{~g}$. per day for one week were effective in diminishing tremor in the majority of patients. Although the effect on blood pressure was almost negligible at this dose for this period, drowsiness and depression were the main side-effects reported.

From this short-term trial it appears that in a dose of 1.0 to $1.5 \mathrm{~g}$. $\alpha$ methyl dopa can modify tremor in Parkinsonism but a further long-term trial is essential for a final assessment of its therapeutic usefulness.

We are grateful to Sister Phillips and her staff for their invaluable help during the double-blind trial, to $\mathrm{Mr}$. Skinner, chief pharmacist, National Hospital, Queen Square, for dispensing the preparations used, and to Dr. Merry, of Merck, Sharp and Dohme Ltd., for the supply of laevo $\alpha$ methyl dopa (Aldomet) and placebo tablets. 


\section{REFERENCES}

Barbeau, A. (1962). Canad. med. Ass. J., 87, 802.

Barcroft, H., Peterson, E., and Schwab, R. S. (1952). Neurology (Minneap.), 2, 154.

Birkmayer, W., and Hornykiewicz, O. (1961). Wien. klin. Wschr., 73, 787.

Brumlik, J. (1962). Neurology (Minneap.), 12, 159.

Carmichael, E. A., Feldberg, W., and Fleischhauer, K. (1962). $J$. Physiol. (Lond.), 162, 539.

Constas, C. (1962). J. Neurol. Neurosurg. Psychiat., 25, 116.

Corne, S. J., Pickering, R. W., and Warner, B. T. (1963). Brit. J. Pharmacol., 20, 106.

Dollery, C. T., Harrington, M., Hodge, J. V., and McMichael, J. (1963). Personal communication.
Domer, F. R., and Feldberg, W. (1960). Brit. J. Pharmacol., 15, 578.

Doshay, L. J. (1961). Extrapyramidal System and Neuroleptics, p. 225. Editions Psychiatriques Case Postale, 6128, Montreal, Canada.

Everett, G. M. (1961). Ibid., p. 182.

McGeer, P. L., Boulding, J. E., Gibson, W. C., and Foulkes, R. G. (1961). J. Amer. med. Ass., 177, 665

Marshall, J., and Walsh, E. G. (1956). J. Neurol. Neurosurg. Psychiat., $19,260$.

Onesti, G., Brest, A. N., Novack, P., and Moyer, J. H. (1962). Amer. J. Cardiol., 9, 863 .

Sannerstedt, R., Varnauskas, E., and Werkö, L. (1962). Acta. med. scand., 171, 75 .

Schnieden, H. (1963). J. Neurol. Neurosurg. Psychiat., 26, 500. 